\title{
UM ENSAIO DE EGO-HISTÓRIA
}

\author{
Eliana Almeida de Souza Rezende \\ PhD e Doutorado em História Social, Linha de Pesquisa Cultura e Cidades pela UNICAMP. \\ Especialista em Preservação e Conservação de Colecções de Fotografia, Lisboa, Portugal \\ Consultora em Gestão de Informação, Gestão de Conhecimento e Memória Institucional \\ Diretora na ER Consultoria| Gestão de Informação e Memória Institucional \\ \eliana@eliana-rezende.com.br
}

\begin{abstract}
Resumo:
Deste universo de informação farta, mas com obsolescência galopante, atuo de forma a encontrar alternativas que conciliem passado, presente e futuro. Afinal, é preciso se colocar diante destes tempos de imediaticidade, produção em massa e, ao mesmo tempo, obsolescências e transitoriedade de suportes. Gosto sempre de incentivar as pessoas interdisciplinarmente. Não creio num mundo compartimentado, creio num mundo que integre vários modos de pensar! É este novo mundo que se descortina para nós. Buscar conexões possíveis entre áreas e manter o espírito aberto para dialogar, e se surpreender, é o que nos deve manter ativos e atuantes.Num mundo de tantos excessos, a importância maior não está em apenas produzir informações, mas essencialmente em distribuir criativamente o que se tem e manter uma inquietação necessária aos acréscimos.Em verdade, minha proposição aqui é muito mais expor uma inquietação provocativa e lançar aos futuros historiadores e demais profissionais das áreas de Ciências Humanas e Aplicadas que lidam com a informação questões em relação ao seu trabalho de investigação e lida com as fontes produzidas na contemporaneidade de princípios do século XXI, suas opções e formas de atuação.
\end{abstract}

Palavras-chave: Historiador, Bibliotecário, Arquivista, Perfil Profissional, Interdisciplinaridade.

\section{AN ESSAY IN EGO-HISTORY}

\begin{abstract}
:
From this abundant information universe, with rampant obsolescence, I work in order to find alternatives that harmonize past, present and future. After all, we must stand before such immediacy, mass production and at the same time, obsolescence and transient media times. I always like to encourage interdisciplinary approaches. I do not believe in a compartmentalized world, I believe in a world that integrates various ways of thinking! It is this new world that's unfolding for us. Search for possible connections between areas and always keep an open mind to dialogue and to be surprised, is what must keep us active and acting. In a world of so many excesses, the most important is not only to produce information, but essentially to creatively distribute what we have and maintain a necessary crave for additions. In fact, my proposal is much more to expose a provocative unrest and offer future historians and other professionals in the fields of Humanities and Applied Sciences dealing with information issues in relation to their research work and dealing with the sources forged in contemporaneity of the early XXIst century, their options and forms of action.
\end{abstract}

Keywords: Historian, Librarian; Archivist; Professional Profile; Interdisciplinarity. 


\section{UM ENSAYO EM EGO-HISTÓRIA}

\section{Resumen:}

De este abundante universo lleno de información, pero con una obsolescencia rampante, actuo con al fin de encontrar alternativas que combinen pasado, presente y futuro. A fin de cuentas, tenemos que enfrentar estos tiempos de inmediatez, producción en masa $\mathrm{y}$, al mismo tiempo, la obsolescencia y transitoriedad de los soportes.Siempre me gusto animar a la gente interdisciplinarmente. ¡No creo en un mundo compartimentado, creo en un mundo que integre diferentes formas de pensar! Es este nuevo mundo que se está desarrollando ante nosotros. Buscar las posibles conexiones entre áreas y mantener una mente abierta para dialogar y ser sorprendido, es para lo que hay que mantenerse activo y actuante.En un mundo de tantos excesos, lo más importante es no sólo producir información, mas esencialmente distribuir creativamente la que se tiene y mantener una curiosidad necesaria para las adiciones.De hecho, mi propuesta aquí es mucho más exponer una inquietación provocante y su lanzamiento a los futuros historiadores y otros profesionales en los campos de Humanidades y Ciencias Aplicadas que se ocupan de cuestiones de información en relación con su trabajo de investigación y se ocupen de las fuentes producidas en la contemporaneidad de principios del siglo XXI, sus opciones y formas de proceder.

Palabras clave: Historiador; Bibliotecário; Archivista; Perfil Profesional; Interdisciplinariedad.

\section{INTRODUÇÃO}

Um ensaio de Ego-História tem lá suas dificuldades. Quando me propus a fazê-lo logo percebi que falar da minha experiência de tessitura de uma carreira seria bem mais difícil do que colocar um tema e desenvolvê-lo. Isso porque falar de si é um exercício de rememoração crítica a partir do presente. Filtros se colocam ante escolhas já feitas e resultadas. E para isso, creio ser importante situar meu ponto de partida e vista. Sou uma humanista com fortes tendências a inter, trans e multidisciplinaridade e isto não surgiu como algo oferecido numa formação universitária, mas sim a partir de demandas e "leituras" do universo em que atuava.

Sou historiadora de formação, arquivista por vocação e, neste caminho cruzado transformações sociais, culturais, tecnológicas, foram determinantes para entender que espaço ocupar com a bagagem que trazia. Herdeira de uma tradição que vinha do mimeógrafo e máquina de escrever, assisti o surgimento, uso e massiva utilização de tablets e smartphones com conteúdos armazenados em nuvem, linkados e hiperlinkados de formas diversas.

Leitores, leitura, produtores e armazenadores de conteúdos e de dados, descobrindo novas formas de se apropriar da informação e produzir conhecimento.

No espaço de minha carreira, o mundo se travestiu e foi preciso entender e atuar de forma a não perder o que se tinha, mas ao mesmo tempo não vagar por um não lugar. 
Em verdade, minha proposição aqui é muito mais expor uma inquietação provocativa e lançar aos futuros historiadores e demais profissionais das áreas de Ciências Humanas e Aplicadas que lidam com a informação questões em relação ao seu trabalho de investigação e lida com as fontes produzidas na contemporaneidade de princípios do século XXI, suas opções e formas de atuação.

O caso do historiador é específico, lida com fontes: rastros, pistas, vestígios deixados, voluntária ou involuntariamente, que atravessam épocas, transpõem espaços, vencem intempéries, descasos, o tempo e as muitas formas de deterioração intrínseca e extrínseca de seus suportes. Tais fontes encontram por parte do ofício do historiador e demais cientistas sociais diferentes usos, e em vários casos funções e pertencimentos que são próprios do fazerse "prova" ou "testemunho". Compõem uma narrativa multifacetada de pessoas, lugares, culturas, sociedades.

Artífices que tecem intrincados caminhos deixados por fontes prováveis e improváveis, os historiadores, transformam-se em porta-vozes de um tempo, de uma trajetória feita por questões e investigações. Conexões são feitas e refeitas, caminhos investigativos desbravados a luz de diferentes métodos e matrizes teóricas. Em muitos casos, o caminho é árduo e construído a partir de hiatos, de não-ditos, de silêncios e omissões. Urde-se a construção de uma trama que circunda um objeto fazendo disso a História, nem certa nem errada, apenas por um ângulo ou prisma diverso. (REZENDE, 2014)

Em todos os casos, tais registros da atividade humana em toda a sua complexidade são fixados em diferentes suportes e por toda a História encontraram suas formas de perenidade para, mais adiante, sofrerem o trabalho crítico de pesquisa e crivo.

Diante de tal complexidade, laboriosa e detalhada, que cada fonte solicita e da quantidade de suportes e de registros de que dispomos, oferece-se ao olhar pesquisador ampla gama de produtos que servirão como fonte de pesquisa e matéria-prima para a História, e em muitos casos para a produção de Conhecimento. (REZENDE, 2014)

De outro lado, vivemos num tempo coetâneo (DUQUE, 2011) em sua essência. Nossa sociedade vive a construção de um novo paradigma sobre a forma como se produz e gere conteúdos e informação.E por isto, a atuação como arquivista surgiu para mim como uma demanda e uma ânsia de continuar a assegurar ao futuro matéria-prima de seu passado. Já que 
o arquivista trabalha no presente, zelando pelo passado para garantir que o futuro tenha uma Identidade a partir de sua herança pregressa.

$\mathrm{O}$ arquivo representa para o historiador a brecha mais desejável, a fotografia de um instante paralisado em palavras do dia a dia, do miúdo. Não nasce como na narrativa historiográfica ou literária a partir de uma intenção de escrita e discurso. Simplesmente acumula-se sucessivamente em pequenos trechos de longas histórias. $\mathrm{O}$ arquivo não nasce para entreter, instruir ou informar. É apenas um instrumento administrativo usado com fins de prova (nos casos de tributos, registros acadêmicos, registros médicos, etc.) e muitas vezes de punição (quando tomamos os casos de arquivos judiciários).

Ao leitor desavisado parecerá que o arquivo possui notas de verdade. Que de repente aqueles nomes, relatos, lugares e acontecimentos falam diretamente a si. Ganham vida numa dança que mistura fantasia e realidade, imaginação e inquietação investigativa. Dos arquivos emerge o vozerio do passado de forma ruidosa e barulhenta nos permitindo um enxergar retalhos de vidas e existências. Nem verdadeiras, nem falsas: apenas prismas.

Esta é magia dos arquivos: a possibilidade do mergulho num outro tempo por meio de registros da vida cotidiana, pequenos delitos, crimes ou desavenças de rua, discursos registrados em atas públicas, ou listas de nomes, impostos, terras. Uma gama sem fim de possibilidades, de personagens, de situações de vida urbana, social, cultural.

É um caminho de conversa com os mortos, mas não estáticos e mumificados, mas cheios de sua vida, de suas urgências e contradições. São despojos de um tempo que temos o privilégio de "tocar", interrogar, conhecer. Muitos nos chegam corroídos, faltando trechos (de palavras, de suportes), consumidos por insetos, enchentes, inundações, e até fogo. São vitoriosos: venceram o tempo!

Os relatos chegam-nos fragmentados, às vezes mutilados. O trabalho minucioso de reunir, organizar e disponibilizar tais fragmentos é a responsabilidade maior do arquivista. Em suas mãos está a possibilidade de narrativas serem construídas, caminhos percorridos, trilhas visitadas. Reunião e organização existem para que a dispersão, fragmentação e novas construções se deem na poderosa urdidura de pesquisadores. Um caleidoscópio de narrativas propiciadas a historiadores e outros pesquisadores pelo trabalho meticuloso de arquivistas. 
Os arquivos são, portanto, feito de excessos: de possibilidades, de falas, de narrativas, de suportes, de informações várias. É horizonte para o que pesquisa e para o que dele cuida.

Por isso meu fascínio e dedicação em ajudá-los a prosseguir em sua missão de perpetuação: ora como historiadora, ora como arquivista.

Diante disso, não é difícil perceber que as preocupações com acervos em diferentes instituições impõem reflexão e aplicação de metodologias e procedimentos que garantam o acesso à informação contida nestes documentos sob os mais variados suportes para as gerações futuras. Seria inadmissível que estes registros não vencessem o tempo e não alcançassem olhos, corações e mentes atentas para deles extrair um relato, um viés, uma interpretação.

Mas arquivos e documentos não se apresentam apenas em formatos analógicos. Foi-se o tempo. Apesar disso, ainda temos nos documentos analógicos a grande concentração de massa documental.

Deste universo de informação farta, mas com obsolescência galopante, atuo de forma a encontrar alternativas que conciliem passado, presente e futuro. Afinal, é preciso se colocar diante destes tempos de imediaticidade, produção em massa e, ao mesmo tempo, obsolescências e transitoriedade de suportes.

\section{O COMPROMISSO PROFISSIONAL DOS PROFISSIONAIS DE INFORMAÇÃO}

Gosto sempre de incentivar as pessoas interdisciplinarmente. Não creio num mundo compartimentado, creio num mundo que integre vários modos de pensar! É este novo mundo que se descortina para nós. Buscar conexões possíveis entre áreas e manter o espírito aberto para dialogar, e se surpreender,é o que nos deve manter ativos e atuantes.

Num mundo de tantos excessos, a importância maior não está em apenas produzir informações, mas essencialmente em distribuir criativamente o que se tem e manter uma inquietação necessária aos acréscimos.

Para tanto, não creio em receitas prontas, e muito menos daquelas que seguem em listas com os 10 pontos, os 6 ou os 5 pontos. Isso não existe! Creio que o primeiro passo efetivo a ser dado é reconhecer que as receitas não servem às pessoas e suas atuações 
profissionais! São eficientes na culinária! E dependendo de quem as faz ainda pode dar errado, só com perdas de ingredientes.

De novo insisto que a questão da interdisciplinaridade me seduz e não consigo pensar em trabalho que não seja assim, em especial quando este se volta à economia social - locus essencial de minha atuação.

Gosto dos grupos e das possibilidades advindas por múltiplos olhares. Em minha experiência vejo a necessidade de muita flexibilidade. É um esforço pessoal, diário e constante, mas me sinto recompensada. Preciso lidar com pessoas de diferentes áreas e formações para que juntos possamos construir nas instituições normas, procedimentos e ações em torno da Gestão de Informação e seu uso para a produção de Conhecimento e Inovação.

No desempenho desta atividade, noto que o grande hiato entre diferentes áreas é a segmentação e, destarte, a dificuldade de interlocução. As pessoas costumam estar sempre muito voltadas para o seu 'centro' e desperdiçam oportunidades de ver o que está ao seu redor. A pretensa busca de especializações criou nichos segmentários e cada vez mais os profissionais sabem menos sobre o que lhe circunda, e onde estão inseridos. Considero isto erro grave nas áreas ligadas às Ciências Humanas e Aplicadas.

Questiono muito sindicalizações e brigas mesquinhas e pequenas sobre quem deve ocupar este ou aquele espaço ou vaga. Fico perplexa em saber da existência de órgãos de controle para inspecionar e multar! A compartimentação acaba sendo responsável por vermos historiadores que não sabem sobre temporalidade documental e usos e aplicações que são da seara da Arquivística.

Arquivistas por sua vez cometem equívocos imensos ao tratar de aspectos relacionados à Memória e na compreensão de conjunturas sociais, culturais, históricas entre outros. Esquecem-se que documentos são produzidos em relações sociais. Bibliotecários perdidos tentando tratar conjuntos documentais arquivísticos como coleções bibliográficas e com um gap imenso em relação a aspectos culturais, sociais e históricos na construção de acervos através do tempo. Sinto que aos historiadores falta uma carga preciosa e técnica de formação para lidar com fontes, documentos, informação. E aos arquivistas, bibliotecários uma formação técnica demais e que os faz ter perdas imensas de leitura e formação social/cultural. Não conseguem compreender relações e inter-relações que acontecem fora de 
normas e procedimentos técnicos. Falta-lhes em boa parte das vezes uma visão mais holística e integrada do campo em que atuam, que é o social. Creio que neste ponto sou muito mais adepta à metáfora do fazedor de pontes. Não deve haver muros nem divisões e acho salutar que as fronteiras sejam movediças e todos troquem suas fontes e aprendam com a flexibilidade. Essa é uma característica muito importante a ser desenvolvida por profissionais concatenados com os novos tempos.

Valorizo muito os que sejam capazes de saber liderar equipes trans e multidisciplinares. Os que conseguem ter sempre uma atitude de facilitador para que trocas e aprendizagens se façam. Para isso acredito muito naquele que tem uma atuação empática e de acesso ao outro: só assim o valor de subsidiar esclarecimento de dúvidas, estímulo à interação e o compartilhamento se efetivarão.

Para mim, os profissionais de Informação neste século XXI precisam ter características especificas. Precisam ser alguém que não apenas conheça, mas que faça circular atributos da cultura social, institucional: valorizando-a e aprimorando-a tanto quanto possível a partir da experiência de todos. Precisam ter espírito curioso e interessado: ser humildes e reconhecer que aprendem sempre, e todos os dias. E mais do que isso: devem ser generosos em partilhar e distribuir o que sabem! Devem ter profundo interesse pelo aprimoramento e aprendizagem não apenas de si próprios, mas de todos os que lhes cercam coletando de cada oportunidade e pessoa o seu melhor.

Ou seja, é preciso ser antes de tudo um bom ouvinte. Se não souber “ouvir” não saberá por onde trilhar. Todos os que lidam com informação precisam entender que não servem a si, mas buscam atender e auxiliar seu usuário/cliente. Como atende-los sem ouvi-los?

De outro lado, noto que as pessoas ao se formarem esperam ter a contrapartida dos anos de estudo, dedicação e, muitas vezes, dinheiro investido, quer em mensalidades, quer em livros e cursos. A estabilidade acaba sendo um grande chamariz para que muitos busquem um concurso público e lá enterrem todos os dias de sua vida. Entretanto, muitos se esquecem de que é preciso ter um perfil para isso. Do contrário, a tão desejada segurança se transformará na mais absoluta prisão. Daquelas que temos as chaves e não conseguimos partir, como se arrastássemos correntes pesadas com bolas de ferro presas aos pés. 
O fim disso todos sabem: resmungões convictos reclamam todo o tempo de rotinas e salários, como se alguém os tivesse obrigado a isso ou aquilo. Impacientam-se e decidem enclausurar-se diante de uma tela classificando e codificando, esquecendo-se que o fim último de tudo o que faz deveria ser a sociedade, o Humano em última instância.

De outro lado, outros tantos sonham com uma carreira Docente numa Universidade Federal ou Estadual. Nada de errado, mas "infelizmente" (coloco entre aspas porque considero correto) o recém Mestre ou Doutor está longe de estar em condições de assumir uma cadeira em qualquer boa Universidade. Precisará construir sua carreira. Muitos desses são o que chamo de "alunos profissionais". São PhD em bolsas, seminários e artigos. Mas falta-lhes o essencial. Só possuem diplomas!

Aqui enveredo para outra coisa importante: ter um diploma não dá uma carreira a ninguém! Mas há uma diferença grande entre profissão e carreira e essa precisa de tempo para se consolidar. Sou muito adepta de que mesmo docentes exerçam funções de consultoria ou afins, para que consigam enxergar as reais demandas de mercado (entendida como a sociedade do mundo real, e não a academia que em muitos casos representa uma bolha ideal). Vejo que, em muitos casos, falta uma perspectiva empreendedora de arriscar: aplicar toda a teoria e quilos de bibliografia para fazer a sociedade rodar.

Enfim, olhar a carreira como uma possibilidade de empreender e inovar em seu ramo de atividade.Ousar ter ousadia, experimentar! Não há espaço para tantos Mestres e Doutores.Terão que definitivamente encontrar formas criativas de se empoderar do seu diploma e conseguir construir uma carreira que faça sentido hoje e que entregue ao futuro uma herança.A sociedade de consumo se estende a tudo e não apenas a objetos materiais. E é em relação a tais temas que temos que pensar.

As dificuldades que encontramos com este novo momento de nossa história educacional coloca-nos o desafio de lidar com um novo conceito de atuação e relação a ser estabelecida entre discentes e docentes, a produção de conhecimento e sua aplicação profissional. A formação geral dos discentes revela que o território da aplicabilidade está sempre muito distante dos livros - pouco se escassamente lidos, diga-se de passagem. A mudança de nomes de disciplinas e conteúdos não é sinal de atualização. 
Em verdade, há que se mudar paradigmas e modelos mentais! O que temos presenciado nas Universidades são novos rótulos para disciplinas, especializações e afins usadas com velhas formas de aplicação. Instigo a todos a pensar que a passividade ante ao dado é que deve ser combatida, e ser amplamente discutida para causar inquietação necessária, para produzir perguntas que mereçam boas construções de soluções para aplicação.

Nunca se deve achar que o diploma é o seu objetivo. Ele é apenas a primeira porta a se abrir.

Lembram-se do Filme Matrix?

\section{REFERÊNCIAS}

BURKE, Peter. A escrita da história. São Paulo, Editora da UNESP, 1992.

CHARTIER, Roger. A ordem dos livros - leitores, autores e bibliotecas na Europa entre os séculos XIV e XVIII. 2 ed. Brasília: Editora UNB, 1998.

CHARTIER. Robert (Org). Práticas de Leitura. São Paulo, Estação Liberdade, 1996.

CUNHA, Maria Teresa. Territórios abertos para a História. In: O historiador e suas fontes. São Paulo, Contexto, 2011.

DUQUE, Cláudio Gottschalg (Org.). Comunicação Científica Contemporânea e de Vanguarda. Ciência da Informação Estudos e Práticas. Brasília: Centro Editorial, 2011.

FARGE, Arlete. O Sabor do Arquivo. Tradução de Fátima Murad. São Paulo, Editora da Universidade de São Paulo (EDUSP), 2009.

FURET, François. A oficina da história. Lisboa, Gradiva, 1985.

HUNT, Lynn. A Nova História Cultural. São Paulo: Martins Fontes. 1992

LÉVY, Pierre. A Revolução contemporânea em matéria de comunicação. Revista FAMECOS, Porto Alegre, n. 9, dez. 1998.

LE GOFF, Jacques. Memória/História. Enciclopédia Einaudi, vol. 1, Lisboa, Imprensa Nacional/Casa da Moeda.

LE GOFF, Jacques. CHARTIER, Roger; REVELL, Jacques. A Nova História. Coimbra, Almedina, 1990.

LE GOFF, Jacques; Nora, Pierre. Histórias: novos problemas, novas abordagens, novos objetos. Rio de Janeiro, Francisco Alves, 1976.

NORA, Pierre. Ensaios de ego história. Lisboa, Edições 70 Ltda., 1989.

PINSKY, CarlaBassanezi; LUCA, Tania Regina (Org.). Apresentação. O historiador e suas fontes. São Paulo: Contexto, 2011. 
REZENDE, Eliana A. de Souza. Em tempos de tintas digitais: escritos e leitores. In: Anais do II Seminário Internacional História do Tempo Presente, Programa de Pós-Graduação em História (PPGH), Universidade do Estado de Santa Catarina (UDESC), Florianópolis, 2014

REZENDE, Eliana A. de Souza. Desafios da contemporaneidade: as tecnologias como política de

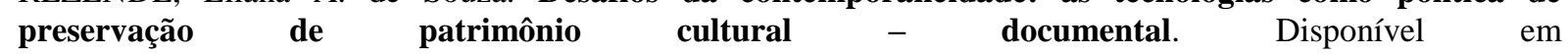
<http://bell.unochapeco.edu.br/revistas/index.php/rcc/article/view/966/53/6 >. Acessado em 23/05/2016.

REZENDE, Eliana A. de Souza. Blog Pensados a Tinta. Disponível em < http://pensadosatinta.blogspot.com.br/ >. Acessado em 23/05/2016. 